\title{
PROGRESOS EN LA PRODUCCIÓN DE TUBERCULOS-SEMILLAS DE PAPA EN LATINOAMÉRICA
}

\author{
Oscar A. Hidalgo*
}

(English Summary at the end)

En la papa propagada básicamente a través de tubérculo- semilla, persisten muchos problemas sanitarios de una estación a otra, ocasionando severas pérdidas en el cultivo. Las semillas de buena calidad garantizan mejores cosechas y son responsables de aumentos significativos en los rendimientos; su producción y usos son por tanto, prioritarios en un país o región. La producción de tubérculos-semillas es una actividad altamente especializada que requiere dedicación de investigadores, extensionistas y productores, para generar, transferir y emplear tecnologías apropiadas que faciliten el desarrollo de esta importante actividad.

Al usar semillas mejoradas o certificadas, se hace casi imprescindible optimizar también otros factores del cultivo como fertilización, riegos, prácticas culturales, control de patógenos, plagas y malezas, etc., que en conjunto facilitan el aumento de la producción y al mismo tiempo la hacen más eficiente y competitiva.

Durante el último decenio en Latinoamérica ha habido notorios avances y aumentos en la producción de tubérculos-semillas de alta calidad. Estas mejoras junto con los factores tecnológicos antes indicados, sumadas a la mayor capacidad empresarial de los productores, han contribuido al mejoramiento significativo de la producción por el aumento en los rendimientos unitarios, pese a que la superficie dedicada al cultivo en Latinoamérica, con ligeras variaciones, se ha mantenido más o menos estable (7).

En el presente trabajo se describen los avances ocurridos en la producción de tubérculo-semilla de papa en Latinoamérica; se analizan tanto los factores tecnológicos involucrados en el

\footnotetext{
* Ph.D., Fitopatólogo, Director Regional, Región I. Centro Internacional de la Papa (CIP). Apartado Aéreo 92654, Bogotá 8, D. E. Colombia.
} 
mejoramiento de los tubérculos-semillas de papa como aquellos relacionados con la decisión de los gobiernos de algunos países para apoyar sus programas de semillas. Se reconoce además la colaboración internacional y la inversión de la empresa privada como factores que han influido significativamente para lograr estos avances.

\section{LA PRODUCCIÓN DE PAPA EN LATINOAMÉRICA Y EN EL MUNDO}

De acuerdo con la información generada entre 1980-82 en Latinoamérica se plantaba aproximadamente el $5 \%$ del área mundial de papa, cifra que significa aproximadamente el $4 \%$ de la producción. En el mundo, los países en desarrollo representan el $40 \%$ del área global plantada y son responsables de aproximadamente el $30 \%$ de la producción mundial (7). En los países desarrollados, la papa es aún más importante y en ellos se plantan y producen las cantidades restantes (60 y $70 \%$ respectivamente). En las Tablas 1 y 2 se presentan datos completos de 1980-82; también se incluye información sobre los países en grupo del Cono Sur, donde en general se obtienen buenos rendimientos y han sido además los países de más altos volúmenes de importación.

TABLA 1. Producción e importación de papa en el mundo, agrupado por principales continentes y nivel de desarrollo, (promedio 1980-82)

\begin{tabular}{lrrrr}
\hline \multicolumn{1}{c}{ Continente/grupo } & $\begin{array}{r}\text { Superficie } \\
(\mathbf{x} \text { 1000 ha) }\end{array}$ & $\begin{array}{r}\text { Producción } \\
\text { (x 1000 t) }\end{array}$ & $\begin{array}{r}\text { Promedio } \\
\text { (t/ha) }\end{array}$ & $\begin{array}{r}\text { Importación } \\
\text { (x 1000 t) }\end{array}$ \\
\hline Latinoamérica & 1.066 & 11.222 & 10.5 & 181 \\
Mundo en Desarrollo & 8.773 & 90.593 & 10.3 & 852 \\
Norteamérica & 605 & 17.627 & 291 & 299 \\
Europa Occidental & 2.111 & 48.052 & 22.8 & 3.072 \\
Mundo Desarrollado & 13.234 & 197.200 & 14.9 & 3.661 \\
& & & & \\
Total Producción del & 22.007 & 287.292 & 13.1 & 4.513 \\
Mundo & & & & \\
\hline
\end{tabular}

Fuente: Horton \& Fano: Atlas de la Papa. 1985 (7). 
TABLA 2. Producción e importación de papa por regiones en Latinoamérica en comparación con los países en desarrollo, (promedio 1980-82).

\begin{tabular}{lrrrr}
\hline \multicolumn{1}{c}{ Región } & $\begin{array}{r}\text { Superficie } \\
\text { (x 1000 ha) }\end{array}$ & $\begin{array}{c}\text { Producción } \\
\text { (x 1000 t) }\end{array}$ & $\begin{array}{r}\text { Promedio } \\
\text { (t/ha) }\end{array}$ & $\begin{array}{r}\text { Importación } \\
\text { (x 1000 t) }\end{array}$ \\
\hline Cono Sur* & 392 & 4.948 & 12.6 & 72 \\
Sudamérica & 956 & 9.879 & 10.3 & 92 \\
Centroamérica y & & & & 91 \\
El Caribe & 111 & 1.352 & 12.2 & 852 \\
Países en Desarrollo & 8.773 & 90.593 & 10.3 & \\
& & & & \\
\hline
\end{tabular}

Fuente: Horton \& Fano: Atlas de la Papa. 1985 (7).

* Incluye: Argentina, Brasil. Chile, Uruguay y Paraguay.

Los promedios de rendimiento en Latinoamérica son muy similares a los reportados para los países en desarrollo. Sin embargo, en tres países del Cono Sur: Argentina, Brasil y Chile los rendimientos superan ese promedio. En los países desarrollados los rendimientos casi duplican o triplican a los obtenidos en los países en desarrollo. En Norteamérica los rendimientos alcanzan hasta 29 t/ha en promedio, pero algunas naciones europeas superan estos niveles. Tanto en Europa Occidental como en Norteamérica es bien conocido el desarrollo de sus respectivos programas de tubérculosemilla, y es también allá donde se originan las exportaciones de este insumo hacia otros países desarrollados y para los del tercer mundo, América, África y Asia.

Con respecto a las importaciones de papa, se debe indicar que si bien algunos países principalmente de Europa se abastecen de tubérculos-semillas de naciones vecinas, sus mayores volúmenes son de papa para consumo provenientes del Norte de África, Chipre o de otros países europeos. En cambio, en las naciones en desarrollo los mayores volúmenes son de tubérculo-semilla, aunque también se han efectuado importaciones para consumo.

Las importaciones de papa para Latinoamérica son principalmente de tubérculo-semilla; sin embargo, algunos países como Venezuela, Cuba y otros del Caribe, así como Perú y Solivia, han importado papa para consumo en forma ocasional.

En cuanto a producción de papa hasta 1981 la situación mundial había sufrido cambios significativos (Figuras 1 y 2). Estos cambios en superficie, producción y rendimiento hasta 1980-82 en el mundo y en sus distintas regiones agrupadas por su desarrollo relativo, han sido reportados por Horton y Fano (7), quienes tomaron como 
base los promedios movibles de 1966-68.

Por otra parte, en los países en desarrollo aumentó la superficie dedicada al cultivo de papa y creció más aún la producción y ambos parámetros se redujeron significativamente en los demás países (Figura 1). Es importante anotar, que si bien, la producción aumentó en Latinoamérica, la superficie no lo hizo en igual proporción (Figura 2a) por lo tanto, esto se debe a aumentos significativos en los rendimientos unitarios (Figura $2 d$ ).
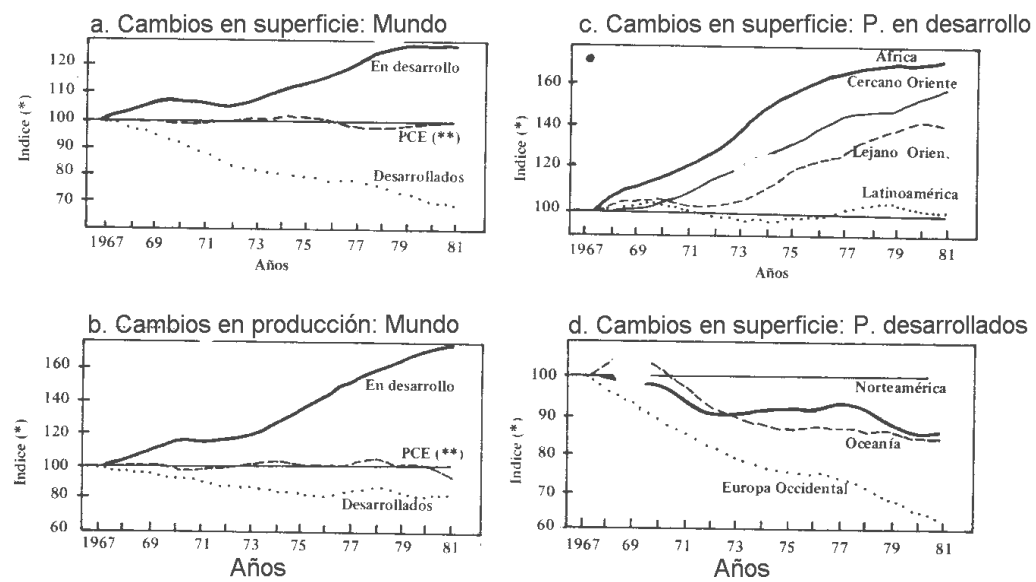

FIGURA 1. Cambios generales en superficie plantada (a) y producción de papa (b) en el mundo y cambios específicos en superficie plantada de papa en los países en desarrollo (c) y desarrollados (d) ocurridos en el período 1967-81.***

\footnotetext{
* Índice relacionado a 100 = Promedio movibles 1966-68

** PEC = Países de Economía Centralizada

*** Fuente: Horton \& Fano, 1985
} 
Este comportamiento no se da en África, donde los aumentos en producción (Figura 2a) están relacionados con el mayor aumento en superficie (Figura 1c) y en menor proporción con los rendimientos unitarios. Para el Cercano y Lejano Oriente, también se han reportado aumentos de rendimientos. La información sobre los países desarrollados se presenta en las Figuras 1 y 2, en las cuales se pueden observar los incrementos en los rendimientos. Sin embargo, en términos relativos en los países del tercer mundo hubo mayores rendimientos con respecto a los otros países. Una buena parte de los incrementos significativos de los rendimientos se deben, entre otras tecnologías del cultivo, al gran desarrollo de los programas de semillas.
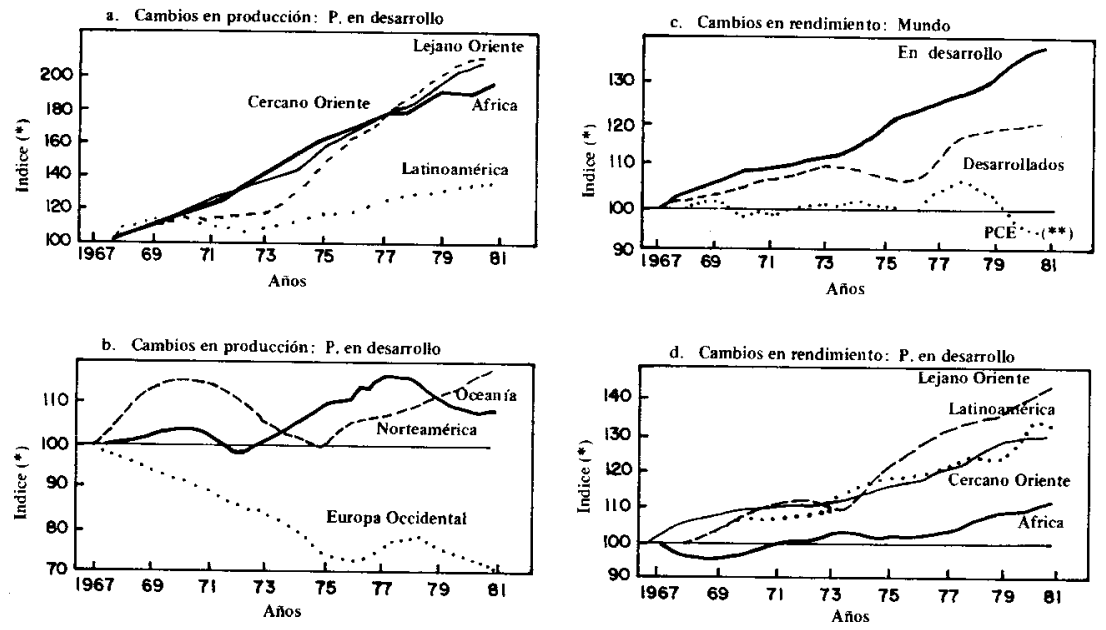

FIGURA 2. Cambios en producción de papa en los países en desarrollo (a) y desarrollados (b) y cambios en rendimiento en el mundo (c) y en países en desarrollo (d) ocurridos en el período 1967-81.**

* Índice relacionado a 100 = Promedios movibles 1966-68.

** PEC = Países de Economía Centralizada

*** Fuente: Horton, D. E.; Fano H. 1985 


\section{SITUACION PREVIA Y ACTUAL DE LOS PROGRAMAS DE PRODUCCIÓN DE TUBERCULO-SEMILLA EN LATINOAMÉRICA}

La producción de tubérculos-semillas de papa en Latinoamérica ha tenido un significativo progreso en los últimos 10-12 años. Este progreso se traduce en el desarrollo de programas de producción de tubérculo-semilla de categoría prebásica, existencia de programas informales o formales de producción de esta semilla, reducción de importaciones, realización de estudios socio-económicos, etc. Estas apreciaciones evaluadas en dos épocas con 10 años de diferencia (1975/76-1986/87), permiten contrastar estas dos realidades y percibir el progreso mencionado en la producción de tubérculosemilla. Las Figuras 3 y 4 muestran estas informaciones para los países de Centroamérica y el Caribe y para Suramérica, respectivamente.

En 1975-76 en Centroamérica y el Caribe existían sólo tres programas informales de tubérculo-semilla: uno en Guatemala, basado en multiplicaciones de materiales locales introducidos de México, otro en Costa Rica fundamentado principalmente en importaciones de Guatemala y algunas veces de México, y el tercer programa conducido en República Dominicana basado en multiplicaciones del material importado de Alemania y Canadá. En esa época Cuba así como otros países del área: Panamá, Nicaragua, Honduras, El Salvador y todas las islas del Caribe, importaban cada año tubérculo-semilla del Canadá, Holanda y EE. UU. para producción de papa consumo (Figura 3a).

De otro lado, el Programa Mexicano se caracterizó desde antes de 1975 por ser un buen programa de multiplicación de tubérculossemillas, basado al comienzo en importaciones de tubérculossemillas de Holanda. México se hizo autosuficiente mediante la implementación de métodos de selección clonal, determinaciones visuales de virus y de reglas de certificación, practicadas en forma disciplinada por un grupo de productores del Valle de Toluca en el Estado de México (12). Por muchos años, el Programa Mexicano de Semillas ha servido como ejemplo de cómo conducir un programa basado principalmente en tecnologías simples y en una estricta disciplina. Actualmente, este programa se ha modernizado con técnicas de multiplicación in vitro, multiplicación rápida y técnicas serológicas para detección de virus. La producción de tubérculosemilla se ha ampliado a otras zonas productoras de México, pero el Valle de Toluca mantiene aún el liderazgo nacional en la producción de tubérculo-semilla (12). 
A)

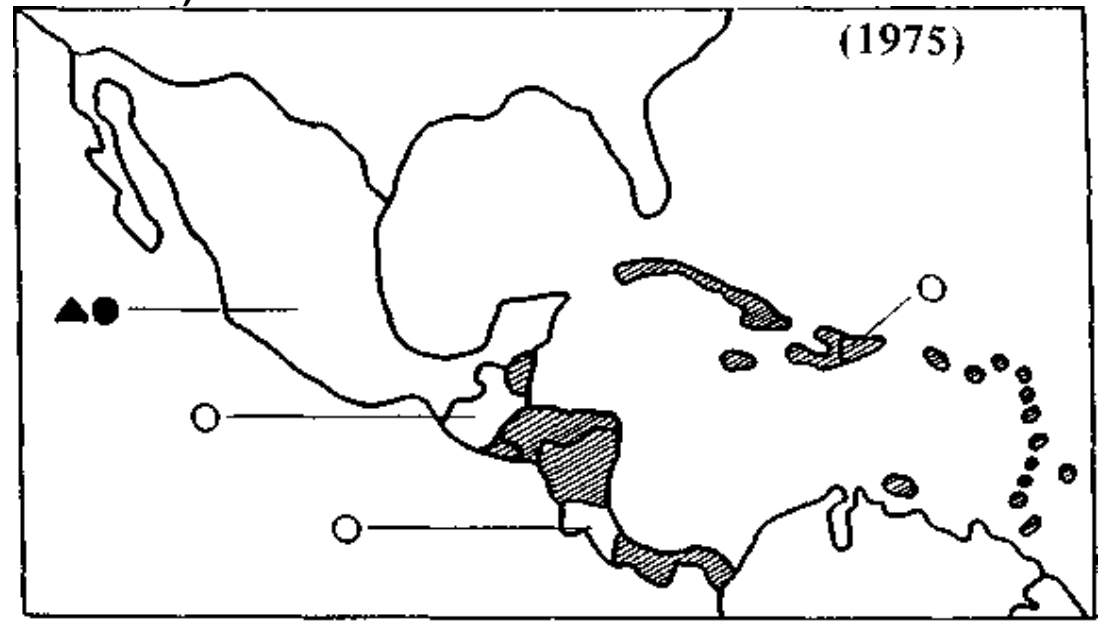

B)

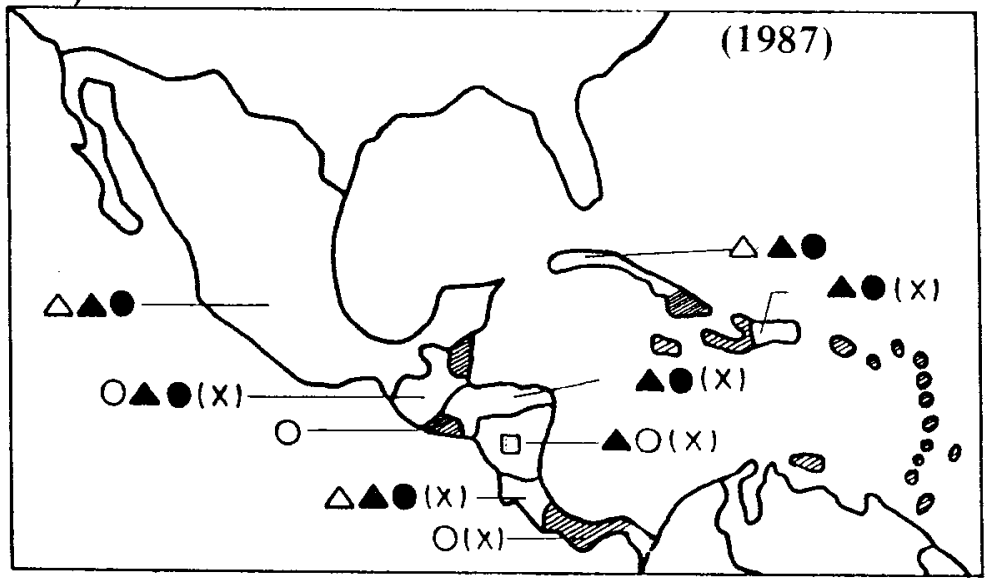

STMBOLOS

$\triangle$ programa de semilla pre-basica

- programa de semilla bastca

O programa informal de semillas

DIIII IMPORTACION PAPA PRODUCIA CONSUMO

programa formal con certiftcacion

$\square$ IMPORTACION PAPF PRODUCIR SEMILLA

EXPORTACION

(x) ESTUDIOS SOCIO-ECONOHICOS

FIGURA 3. Cambios en la situación de la producción e importación de tubérculos-semillas de papa en los países de Centroamérica, Panamá, México y El Caribe. Situación en 1975 \{a) y cambios ocurridos hasta 1987 (b). Compilado por O. Hidalgo, Agosto, 1987. 
A)

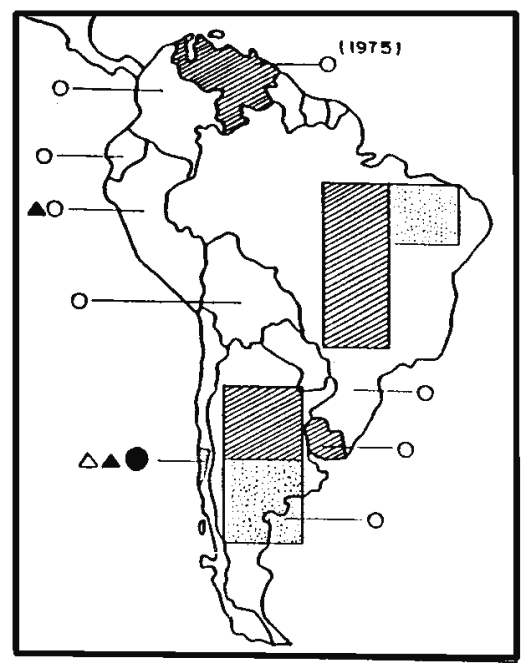

SIMBOLOS

$\triangle$ Programa de semilla pre-basica

- programa de semilla basica

O PRograma informal de semillas

- programa formal con certificacion

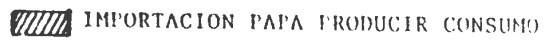

$\square$ IMPORTACION PAPA PRODUCIR SEMILLA

EXPORTACION

(X) ESTUdIOS SOCIO-ECONOMICOS

B)

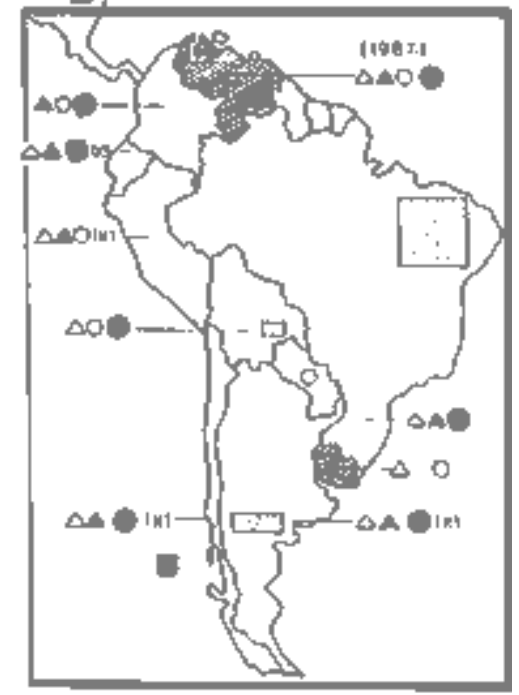

FIGURA 4 Cambios en la situación de la producción e importación de tubérculos-semilla de papa en los países de Suramerica. Situación en 1975 (a) y cambios ocurridos hasta 1987 (b). Compilado por O. Hidalgo, Agosto 1987. 
Además de los progresos obtenidos por México, otros programas nacionales, entre ellos los de Cuba y República Dominicana en el Caribe han tenido éxito, en especial el de Cuba, donde se ha establecido un programa de producción con instalaciones especialmente construidas para tales fines. Las importaciones se han reducido en forma significativa en Cuba y en República Dominicana se han suprimido totalmente; en este último país existe en la actualidad un Centro de Producción de Semilla Básica y un Programa Formal de Certificación $(4,5)$.

En Centroamérica el progreso ha sido también notorio; prácticamente todos los países del área cuentan con programas eficientes ya sean formales o informales. Las importaciones de tubérculos-semillas se han reducido en forma notable y aquellos que aún se importan se multiplican para producirlos localmente. Costa Rica y Honduras tienen programas de producción de tubérculos-semillas de categoría básica fundamentados en diferentes esquemas de producción; el de Costa Rica está basado en la producción de tubérculos-semillas de categoría prebásica a través de multiplicación rápida y el programa de Honduras se fundamenta en la multiplicación de material importado de categoría Elite (R. Rodríguez, Comunicación Personal, Panamá 1988). Guatemala y Costa Rica disponen ya de programas de producción de tubérculos-semillas de categoría prebásica. Panamá, aún cuando se mantiene como importador de tubérculos-semillas, ha reducido su importación en casi $60 \%$, debido principalmente al aumento de la vida útil de las mismas y al uso de mejores cultivares con resistencia a virus que pueden multiplicarse localmente por más generaciones (R. Rodríguez, Comunicación Personal, Panamá 1988).

Los programas en América del Sur (Figura 4) se agrupan de acuerdo con la especie que cultivan: los países andinos plantan Solanum tuberosum subsp. andigena y los del Cono Sur y también Venezuela cultivan $S$. tuberosum subsp. tuberosum; en Bolivia además de la subsp. andigena se cultiva la subespecie tuberosum. El desarrollo de los programas de tubérculo-semilla en los países de cada una de estas subregiones es, por lo tanto, diferente debido a la naturaleza misma de cada subespecie involucrada. La diferencia fundamental consiste en que los programas que trabajan con la subespecie tuberosum pueden utilizar tubérculos-semillas importados del hemisferio norte, puesto que se trata de la misma subespecie. Sin embargo, esto no es posible en los países de la zona andina que dependen de sus propios cultivares y programas para obtener sus tubérculos-semillas.

Las zonas de la región andina han influido en la preservación de cultivares nacionales con un nivel de sanidad relativamente alto. En estas regiones se ha facilitado el establecimiento de programas 
informales de producción de tubérculos-semillas que, a pesar de ser eficientes, aún pueden mejorarse con la inclusión de técnicas como cultivos in vitro, multiplicación rápida y pruebas serológicas. En todos estos países se han realizado estudios socioeconómicos que han permitido entender mejor los sistemas informales y dimensionar los programas para satisfacer las necesidades de cada país o región. Es importante destacar el marcado éxito de los programas de tubérculo-semilla de categoría básica establecidos en Perú (13), Ecuador (9) y Venezuela (1), los cuales hacen uso eficiente de los métodos de multiplicación rápida, cada uno con características propias y que satisfacen parcialmente las necesidades de semilla en sus respectivos países. Bolivia, a su vez, ha iniciado un programa de tubérculo-semilla de categoría prebásica mediante la importación de pequeñas cantidades del tipo tuberosum, las cuales se plantan en la región mesotérmica oriental del país; además se ha utilizado con éxito la multiplicación rápida.

Los programas de los países del Cono Sur y Venezuela que cultivan la subsp. tuberosum, se han basado -y algunos de ellos aún lo hacen- en las importaciones de material de buena calidad para multiplicarlo por una o más generaciones o algunas veces para usarlas como material de plantación para producir papa para consumo. Todos los países del Cono Sur, con excepción de Chile, se caracterizaron en la época de 1975-76 por ser importadores/multiplicadores, a pesar de que todos ellos tenían programas informales de tubérculos-semillas con programas incipientes de certificación. Sin embargo, el Programa Chileno para 1975-76 tenía ya bien desarrollada la producción de esta semilla de categoría pre-básica y básica empleando los métodos tradicionales de "índice de tubérculo" e "índice de planta" y en la clásica "multiplicación clonal" tan eficiente como en los mejores programas de tubérculos-semillas del mundo hasta esa época (11).

Gran parte del éxito del Programa de Tubérculo-semilla de Chile desde su inicio en la década del 70 , se debió principalmente a las buenas condiciones naturales de la zona productora de tubérculosemilla en el sur del país y a un programa disciplinado y eficiente de certificación (11).

Durante 1986-87 la mayoría de los países del Cono Sur y también Venezuela, han mejorado notoriamente sus anhelos de autoabastecerse de tubérculos-semillas. Las importaciones de esta semilla en Argentina, Brasil y Chile fueron desde hace algunos años motivo de regulaciones, las cuales incentivaron un desarrollo rápido de los programas nacionales respectivos, y a su vez fueron debidamente reforzados con nueva tecnología y con capacitación a los técnicos.

Desde hace varios años Chile ya no importa tubérculos-semillas; 
Argentina lo hizo hasta 1985 y Brasil ha reducido sus importaciones, limitándolas en la actualidad a materiales superiores para multiplicación y obtención de más tubérculos-semillas.

De otro lado, Venezuela a pesar de haber desarrollado en los últimos años un buen programa de tubérculo-semilla de categoría prebásica, aún no ha podido superar algunos factores de organización y arancelarios, que hacen todavía a este país dependiente de grandes volúmenes de material importado ( $E$. Ortega, Comunicación Personal, Venezuela 1988).

Uruguay a su vez no ha podido desarrollar su programa de tubérculo-semilla y se mantiene como país netamente importador. Allí, en los últimos ocho años se han llevado a cabo varios intentos de producir y multiplicar tubérculos-semillas, pero no se ha tenido éxito por falta de apoyo institucional y político. Recientemente, un nuevo programa de producción de tubérculos-semillas de la categoría prebásica se inició en el Uruguay. En 1987, con la participación de todos los sectores interesados, se creó en el Ministerio de Ganadería, Agricultura y Pesca del Uruguay la Comisión de Certificación de Papa-Semilla, la cual empezó su actividad con 250 ha inscritas. Esta vía será transitoria hasta cuando la producción y multiplicación de semilla de la categoría prebásica, ya iniciada, cubra las necesidades de semilla básica del país (C. Crisci, Comunicación Personal, Uruguay 1988).

Por otra parte, con la colaboración técnica del CIP, se estableció en el Paraguay en 1986, el Programa Nacional de Papa, el cual ha iniciado estudios básicos sobre las posibilidades de producción de semilla en el país, entre otros.

En Argentina, Brasil y Chile gran parte del éxito en la producción de tubérculos-semillas de las categorías prebásica y básica se debe fundamentalmente al apoyo institucional, en especial en el caso del Brasil, con la creación y funcionamiento del Servicio de Producción de Sementes Básicas (SPSB) de la EMBRAPA que inició sus actividades al final de la década del 70. Además, por la decisión de empresas privadas de invertir en la producción de tubérculossemillas, como en Brasil y Argentina. Durante los últimos años, en ambos países se han creado diferentes empresas dedicadas a la producción de mini y microtubérculos producidos en ambientes controlados. En Argentina, también existe una empresa privada dedicada al diagnóstico y apoyo a la certificación.

El Programa Chileno de Semilla modificó su sistema de producción de tubérculo-semilla de categoría prebásica a partir de 1987 . En años anteriores esta producción estuvo basada principalmente en la multiplicación clonal, la cual está siendo remplazada por un sistema de multiplicación in vitro y de multiplicación rápida, con el fin de disminuir el número de generaciones en el campo y evitar, de ser factible, contaminaciones del "pie negro" y "pudriciones blandas" 
inducidas por Erwinia spp. Este nuevo sistema de multiplicación ya está en operación y en lo posible será combinado con la multiplicación clonal (10). Durante 1984 y 1985 se efectuaron estudios agroeconómicos en el Programa Chileno con la colaboración del CIP, con el propósito de evaluar la eficiencia del programa, lo mismo que para medir la demanda real de tubérculossemillas, y obtener valiosa información sobre los "escapes" de semilla del Servicio de Certificación, principal problema del Programa de Semillas (8). Estudios similares se han realizado en la Argentina, también con la colaboración del CIP. Finalmente, es importante mencionar que desde hace algunos años una empresa privada chilena inició exportaciones de tubérculos-semillas a varios países latinoamericanos (11).

Resumiendo, los avances en la producción de semilla en Latinoamérica han sido notables en la última década, lo cual coincide con los esfuerzos nacionales y con los del CIP en generación, transferencia de tecnología y capacitación, efectuados en este período.

\section{DECISIONES GUBERNAMENTALES Y FACTORES TECNOLÓGICOS Y DE CAPACITACIÓN QUE HAN PERMITIDO AVANCES}

\section{Decisiones Gubernamentales}

Entre los factores que han facilitado el avance de los programas de tubérculo-semilla en Latinoamérica, el más importante quizá tiene que ver con las decisiones gubernamentales de los países de llevar a cabo una o dos de las siguientes acciones, según sea el país involucrado:

a) Creación y/o fortalecimiento de los Programas de Semillas, en lo cual han tenido también participación activa las redes regionales de colaboración (PRECODEPA*, PRACIPA ${ }^{* *}$ y PROCIPA $^{\text {*** }}$, el CIP y en algunos casos las agencias internacionales de colaboración).

\footnotetext{
*PRECODEPA: Programa Regional Cooperativo de Papa. ${ }^{* *}$ PRACIPA: Programa Andino Cooperativo de Investigación en Papa.

${ }^{* * *}$ PROCIPA: Programa Regional de Investigación en Papa.
} 
b) Reducción ordenada de las importaciones en algunos de los países que utilizan la subespecie tuberosum, para dar el espacio necesario al fortalecimiento y desarrollo de los programas nacionales de tubérculo-semilla. Esta reducción permitió que empresas nacionales empezaran a producir con ventajas, aquello que estaba dejando de ser importado. Los casos más notorios, como ya fue señalado, han sido los del Brasil, Argentina, Cuba, Honduras, República Dominicana y Nicaragua, principalmente. Los esfuerzos de Venezuela y Panamá en este sentido han sido también muy significativos. Uruguay, país también importador, no ha logrado aún implementar integralmente su programa de tubérculo-semilla, aunque tiene toda la tecnología y condiciones para hacerlo.

Un estudio de la demanda para 1976-77 y la proyección para 1988 de tubérculos-semillas importados en cuatro países suramericanos fue realizado por una Empresa Consultora chilena: E. I. Consultores (3). Este estudio concluyó que de mantenerse los niveles de demanda de aquella época, la proyectada para 1988 aumentaría significativamente para Brasil y Venezuela, y en menor proporción para el caso de Argentina y Uruguay. Según el estudio, mantendrían más o menos iguales sus niveles de demanda por tubérculossemillas importados. Estos datos están indicados en la Tabla 3, donde se presenta información sobre los países proveedores, precios del tubérculo-semilla en ese momento e informaciones sobre la demanda real en los últimos 5 a 8 años.

En Argentina las importaciones se han reducido significativamente desde la campaña 1983-84. En este período, sólo se ha permitido importar pequeñas cantidades de materiales de altas categorías y material experimental. Para la campaña 1987-88 la decisión y la expectativa era también de no importar. En el caso de Brasil, la importación de tubérculos-semillas se ha reducido progresivamente de casi 17.200 t en 1978 a sólo 3.900 t en 1987 (Figura 5). En esta época el Ministerio de Agricultura eliminó toda importación que no fuera para producir más tubérculossemillas. Uruguay ha mantenido sin mayores cambios los mismos niveles de importación de tubérculos-semillas. Venezuela (Figura 6) los ha aumentado significativamente (10). En promedio, el Uruguay (BROU/NADI) dedicó casi 3 millones de dólares por año y Venezuela (10) alrededor de 5.8 millones de dólares anuales para importar tubérculossemillas de papa, especialmente de Canadá. 
TABLA 3. Demanda actual y potencial, proveedores y precios de semillas importadas en cuatro países suramericanos en el año 1976, proyectada para 1988, en comparación con la demanda real actual ** en períodos de 5 a 8 años (1980-83 a 1987) en los mismos países.

Situación

Argentina Brasil Uruguay Venez. Total

Demanda (x $1000 \mathrm{t})^{*}$

- Actual (76/77)

11.5

13.5

11.0

13.0

49.0

- Proyección (1988)

13.1

18.9

11.7

18.0

61.6

Proveedores (\%)*

- Canadá

80.

- Holanda

- Alemania

$\begin{array}{cc}20.0 & 70.0 \\ -\quad 10.0\end{array}$

100.0

90.0

- $\quad 10.0$

- Suecia

- $\quad 20.0$

Precios promedios*

(CIF/US\$/t)

- Var. Canadá

$250-230$

250

- Var. Europa

$500.0 \quad 550.0 \quad 500.0$

Demanda real

$(1000 \mathrm{t})^{\star * * * *}$

Actual (Promediolaño)

0.0

4.5

11.5

Período

\footnotetext{
* Fuente: E.I. Consultores Ltda./CORFO (Chile). 1979 (3).

** Fuentes oficiales de los países.

*** Fuente: Niño de Gualdrón L., 1988 (10).
} 


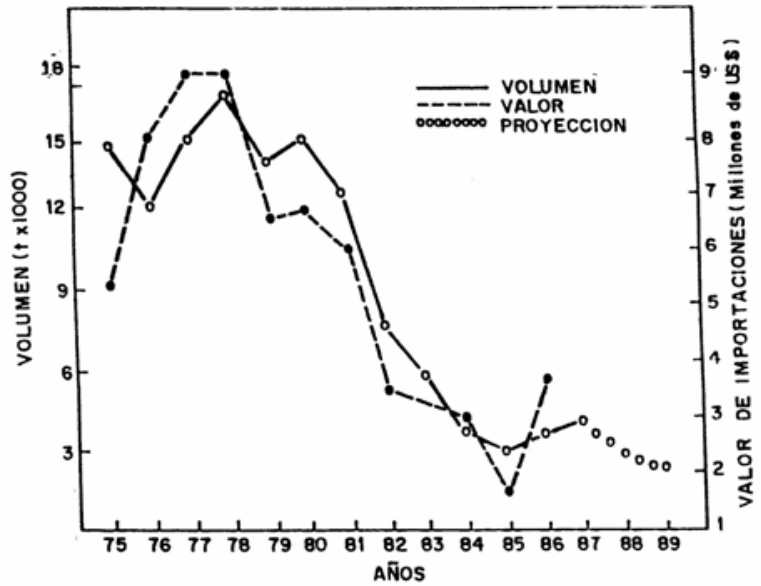

FIGURA 5. Volumen, valores y proyecciones de las importaciones de tubérculos-semillas de papa al Brasil en el período 1975-86/88.

Fuente: Ministerio de Agricultura/EMBRAPA/CACEX.

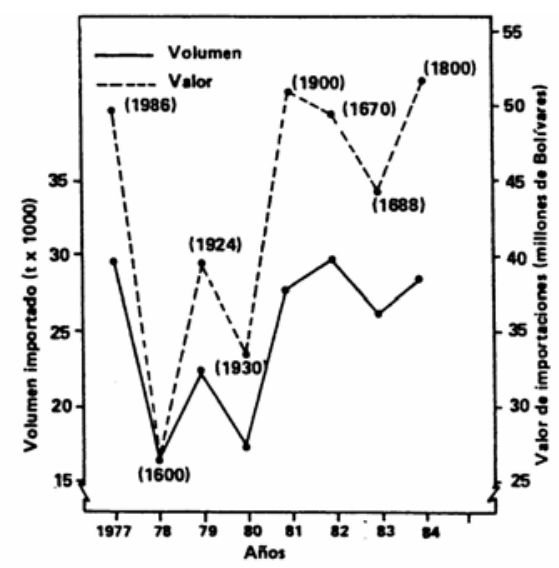

FIGURA 6. Volumen y valor de las importaciones de tubérculossemillas de papa a Venezuela en el período 1977-1984. Números en paréntesis indican precio por tonelada en bolívares.

Fuente: Niño de Gualdrón (10). 
Las decisiones gubernamentales de Brasil y Argentina de reducir o controlar las importaciones de tubérculos-semillas de papa permitieron y favorecieron el desarrollo rápido de los Programas Oficiales de Semillas. Estos, a su vez, patrocinaron e impulsaron programas semejantes en empresas privadas, los cuales están en operación en ambos países; el espacio dejado por la reducción de las importaciones fue inmediatamente ocupado por las empresas nacionales.

\section{Factores Tecnológicos}

La disponibilidad de tecnología ya conocida y adaptada a las condiciones locales permitió que las decisiones gubernamentales tuvieran éxito.

La selección y reproducción clonal así como la aplicación de las normas de certificación que han sido usadas por los programas de semillas, siguen siendo las metodologías bases para conseguir y mantener tubérculos-semillas de alta sanidad. Los recientes progresos en la producción de esta semilla se deben sin embargo a los siguientes factores tecnológicos:

a) Pruebas serológicas. Las observaciones visuales en el campo y las determinaciones de virus usando plantas indicadoras fueron paulatinamente remplazadas, primero, por las pruebas serológicas de microprecipitación y luego por las pruebas de Látex, ELISA y NASH para detección de virus y viroides, respectivamente. Las determinaciones visuales en el campo, son aún la "herramienta" más usada en la Certificación de Semillas.

b) Multiplicación rápida. A finales de la década del 70, estas técnicas estaban ya suficientemente difundidas y usadas por varios países latinoamericanos (1). Los esquejes de tallo lateral, tallo adulto, tallo juvenil, brote y la integración de los mismos hicieron posible una real multiplicación rápida de pequeñas existencias de materiales libres de patógenos, con lo cual se dio inicio a los programas de producción de tubérculos-semillas de categoría prebásica.

c) Cultivos in vitro. La simplificación y multiplicación de tejidos vegetales in vitro facilitó inicialmente la obtención de plantas 
madres y luego, con la "desmitificación" de la técnica se popularizó la multiplicación in vitro, que aumentó aún más la eficiencia de la multiplicación rápida.

En la actualidad, prácticamente todos los países suramericanos llevan a cabo combinaciones de métodos de multiplicación rápida en planta e in vitro, para producir tubérculos-semillas de categoría prebásica en una escala comercial (1). En Centroamérica y el Caribe, por lo menos en cinco países, estas técnicas están siendo usadas en gran escala.

d) Producción local de antisueros. El uso de técnicas de multiplicación rápida requiere un control de calidad más eficiente, especialmente de los virus transmitidos en forma mecánica. Las pruebas serológicas (Látex, ELISA) se popularizaron pronto debido a la difusión de conjuntos serológicos experimentales y a la masiva capacitación en técnicas serológicas también ofrecida por el CIP.

Los antisueros requeridos inicialmente fueron en parte suministrados en pequeña escala por el CIP para uso en los programas nacionales; para multiplicaciones en gran escala, fueron importadas de Europa.

La producción local de antisueros para atender las necesidades nacionales fue siempre reconocida como urgente. Un plan de dos etapas patrocinado y apoyado por el CIP desde 1983, llevó al CNP-Hortalizas de la EMBRAPA-Brasil a lanzar en la Etapa I un Conjunto Serológico de Látex y luego, uno de ELISA para la detección de los principales virus de cultivos (PVX, PVY, PVS, PLRV), basados en sueros crudos producidos por el CIP pero procesados en el Brasil. La Etapa II, en gran parte ya cumplida, se inició al mismo tiempo con la Etapa I y ha hecho posible que los antisueros más importantes sean producidos localmente en todas sus etapas por el CNPHortalizas, mediando la colaboración técnica del CIP. El Programa Argentino ha cumplido con la Etapa I y ha iniciado con éxito la Etapa II.

En 1987 el INTA-Córdoba lanzó con éxito al mercado nacional dos conjuntos serológicos (Látex y ELISA) para uso comercial entre los productores de tubérculos-semillas y otros usuarios potenciales de los mismos.

La estrategia para abastecer de antisuero a los países miembros del PRECODEPA en Centroamérica y el Caribe siguió un mecanismo diferente. En este caso, el CIP como 
miembro activo de esta red regional, fue el responsable de producir, distribuir los antisueros y capacitar en su uso a los demás miembros de la organización. En la actualidad, todos los países miembros del PRECODEPA y en especial aquellos con programas de producción de tubérculo-semilla de categoría prebásica (México, Cuba, Costa Rica, Guatemala y en parte República Dominicana) están usando rutinariamente las pruebas de Látex y ELISA.

e) Estudios agroeconómicos. Esfuerzos aislados pero significativos en las investigaciones sobre los diferentes aspectos relacionados con la producción de tubérculossemillas, se han realizado principalmente en los países del Cono Sur de Suramérica. De otro lado, varios de los países miembros del PRECODEPA han llevado a cabo estudios agrosocioeconómicos de los programas de producción de semillas, así como en la mayoría de los países de la zona andina y en dos países del Cono Sur (Chile, Argentina). Estos estudios han definido en parte los flujos tradicionales, la demanda, la taza de reuso de los mismos y varios otros aspectos agroeconómicos importantes para los programas de tubérculo-semilla. Particularmente, interesantes son los estudios realizados en los países de la zona andina, donde se ha demostrado el valor de los programas informales (tradicionales) para mantener la calidad fisiológica $y$ sanitaria, debido a las excelentes condiciones naturales de altitud y de aislamiento. La Tabla 4 presenta un ejemplo de algunos de los resultados obtenidos en un estudio conducido por INIA y CIP en Chile $(2,8)$. Se ha estimado que la demanda de tubérculos-semillas de papa en Chile es de casi 28.000 t (aprox. 20\% de las exigencias teóricas), con base en estudios de campo que permitieron además entender mejor el flujo y la demanda de tubérculos-semillas por regiones $(2,8)$.

\section{Capacitación y Asistencia Técnica}

Mediante la capacitación en servicio o en cursos formales realizados a través de los años, se ha cumplido en parte, con la transferencia de tecnología. Igualmente, las visitas de científicos del CIP, así como los intercambios de científicos entre países han ayudado a que las tecnologías antes mencionadas se difundan rápidamente. Varias son las instituciones nacionales e internacionales que han ofrecido capacitación en producción de tubérculo-semilla y en áreas relacionadas, entre éstas, CIP ha desempeñado un papel preponderante. A manera de ejemplo, la Tabla 5 indica el número de técnicos nacionales de los países no-andinos de Latinoamérica que han recibido capacitación en distintos 
TABLA 4. Estimación de la demanda de tubérculos-semillas de papa en Chile disgregada por regiones geopolíticas.

\begin{tabular}{llccc}
\hline $\begin{array}{l}\text { Región del país } \\
\text { (de Norte a Sur) }\end{array}$ & $\begin{array}{c}\text { Requerimientos } \\
\text { teóricos de } \\
\text { semilla }\end{array}$ & $\begin{array}{c}\text { \% de semilla } \\
\text { comprada }\end{array}$ & $\begin{array}{c}\text { Estimación } \\
\text { demanda (t) }\end{array}$ \\
\hline IV (Norte) & 8.850 & 46 & 4.071 \\
V $\quad$ (Norte) & 5.100 & 57 & 2.907 \\
R.M. (Santiago) & 6.450 & 57 & 3.677 \\
VI (Sur) $\quad$ (Sur) & 5.250 & 57 & 2.993 \\
VII $\quad$ (Sur) & 22.350 & 20 & 4.470 \\
VIII (Sur) & 26.850 & 20 & 5.370 \\
IX (Sur) & 22.050 & 6 & 1.323 \\
Total & 96900 & & 24811 \\
\hline
\end{tabular}

Fuente: Cobarrubias. 1984 y Monares et al. 1988.

tópicos en cursos ofrecidos o patrocinados por el CIP, especialmente en los últimos 5-6 años. En la Tabla 6 se puede apreciar que 65 y $43 \%$ de los esfuerzos de capacitación en los países del Cono Sur y en los países miembros de PRECODEPA, respectivamente, han sido dedicados a reforzar la producción de tubérculos-semillas y aspectos relacionados tales como: virología, cultivo de tejidos, patología y producción integrada de la categoría prebásica. Se reconoce ampliamente los esfuerzos dedicados a la capacitación de técnicos nacionales, pues ello es uno de los fundamentos básicos del progreso alcanzado en la producción de tubérculos-semillas en Latinoamérica.

\section{COLABORACIÓN INTERNACIONAL}

Se reconoce que antes de 1976-77 varias instituciones internacionales ofrecieron asistencia técnica con programas formales o informales de trabajo. En este relato se incluirá sólo la participación de las principales instituciones internacionales y empresas privadas, ocurrida a partir de esa fecha en concordancia con el período analizado.

Desde su fundación en 1972, el Centro Internacional de la Papa dio el debido apoyo a los programas de tubérculo-semilla en Latinoamérica, mediante cursos y visitas técnicas cuando así fue solicitado. 
TABLA 5. Capacitación en el cultivo de papa en los países del Cono Sur y de PRECODEPA llevada a cabo ylo patrocinada por el CIP hasta 1987*.

$$
\text { Número de técnicos capacitados }
$$

Área de Argent. Brasil Chile Urug. Parag. PREC. Total $\begin{array}{lllllll}\text { Capacitación } & 78 / 87 & 82 / 87 & 82 / 87 & 82-87 & 86 / 87 & 78 / 87\end{array}$

\begin{tabular}{|c|c|c|c|c|c|c|c|}
\hline $\begin{array}{l}\text { Producción de } \\
\text { Semilla }\end{array}$ & 64 & 75 & 44 & 4 & 11 & 49 & 247 \\
\hline Virología & 7 & 4 & 4 & 2 & - & 16 & 33 \\
\hline $\begin{array}{l}\text { Cultivos tejid. } \\
\text { y Mult. rápida }\end{array}$ & 11 & 6 & 3 & 1 & 1 & 5 & 27 \\
\hline $\begin{array}{l}\text { Patología de } \\
\text { Semillas }\end{array}$ & 14 & 3 & 4 & 1 & - & 6 & 28 \\
\hline Almacenam. & 4 & 4 & 3 & 1 & - & 13 & 25 \\
\hline $\begin{array}{c}\text { Manejo de } \\
\text { Germoplasma }\end{array}$ & 3 & 4 & 3 & 2 & 1 & 11 & 22 \\
\hline $\begin{array}{l}\text { Nematología y } \\
\text { Entomología }\end{array}$ & 2 & 3 & 3 & 2 & 1 & 13 & 24 \\
\hline $\begin{array}{c}\text { Semilla } \\
\text { Verdadera }\end{array}$ & 2 & 2 & 1 & 0 & 1 & 15 & 21 \\
\hline Producción & 12 & 15 & 3 & 2 & 16 & 11 & 59 \\
\hline $\begin{array}{c}\text { Conferencias y } \\
\text { otros }\end{array}$ & 10 & 18 & 17 & 7 & - & 37 & 89 \\
\hline Total & 129 & 134 & 85 & 21 & 30 & 176 & 575 \\
\hline Promediolaño & 15.2 & 29.8 & 18.9 & 4.0 & 15.0 & 21.0 & \\
\hline
\end{tabular}

PRECODEPA $=$ Programa Regional Cooperativo de Papa.

* Fuente: Informes Anuales y de Progreso (1982 a 1987) de la Región II del CIP. Datos compilados por O. Hidalgo. 1987. 
A finales de la década del 70, el CIP tenía ya consolidados sus programas de multiplicación rápida, virología, producción de antisueros, cultivo de tejidos, etc., sobre los cuales los programas regionales del CIP hicieron una activa transferencia de tecnología (6). EI CIP también puso a disposición de los países material genético y cultivares comerciales que habían pasado las pruebas para patógenos; estos cultivares fueron usados en los distintos programas de multiplicación rápida e in vitro. Además, el CIP ofreció y sigue ofreciendo un servicio para eliminar patógenos de los principales clones y cultivares nacionales. También se llevó a cabo un programa activo de capacitación (Tablas 5 y 6), sólo en el período de 1982-87, el CIP propició 3 cursos internacionales de semillas en Argentina, 5 en Brasil, 2 en Chile, además de cursos nacionales en Uruguay (1) y Paraguay (2). Así mismo, se realizaron otros cursos relacionados en la sede del CIP en Lima, así como en otras regiones del CIP. La capacitación individual más especializada principalmente en virología y cultivo de tejidos fue llevada a cabo en Lima, sede central. Es difícil establecer la medida en que la capacitación y asistencia técnica ofrecida por el CIP, han contribuido directamente al progreso de los programas de tubérculo-semilla de Latinoamérica, pero sin lugar a dudas, la colaboración del CIP ha sido el factor principal para que esto ocurra tal como ha sido reconocido por los distintos programas nacionales (6).

El CIP participa y ha contribuido para promover y organizar tres Redes Regionales de Investigación y Transferencia de Tecnología: PRECODEPA, PRACIPA y PROCIPA. Las dos primeras están en operación con apoyo de donantes, y la tercera espera aún un donante apropiado para iniciar oficialmente sus acciones.

Desde su establecimiento en 1978 el PRECODEPA cuenta con el apoyo financiero de la Cooperación Suiza para el Desarrollo (COSUDE), la cual además ofrece apoyo en colaboración con el CIP a los programas de tubérculos-semillas de Honduras, Perú y Bolivia. Para el caso del PRACIPA, la red de investigación regional que aglutina los países andinos en asuntos de papa, tiene el apoyo del Centro de Investigaciones para el Desarrollo del Canadá (CIID) y del CIP. 
TABLA 6. Resumen de la capacitación en producción de tubérculossemillas y otras áreas de la producción de papa llevada a cabo ylo patrocinada por el CIP en los países del Cono Sur y PRECODEPA hasta 1987*.

Número y \% de técnicos capacitados

\begin{tabular}{lcccccc}
\hline $\begin{array}{l}\text { Área de } \\
\text { Capacitación }\end{array}$ & $\begin{array}{c}\text { Países Cono Sur } \\
\text { No. }\end{array}$ & $\begin{array}{c}\text { PRECODEPA } \\
\text { No }\end{array}$ & No. & \multicolumn{2}{c}{ Total } \\
\hline $\begin{array}{l}\text { Producción } \\
\text { de Semilla }\end{array}$ & 259 & 65 & 76 & 43 & 335 & 58.0 \\
$\begin{array}{l}\text { Producción } \\
\text { Conferencias }\end{array}$ & 58 & 22 & 63 & 36 & 151 & 26.0 \\
& 52 & 13 & 37 & 21 & 89 & 16.0 \\
\hline Total & 399 & 100.0 & 176 & 100.0 & 575 & 100 \\
\hline
\end{tabular}

* Fuente: Informes Anuales y de Progreso (1982 a 1987) de la Región II del CIP. Datos compilados por O. Hidalgo. 1987.

\section{ROL DE LAS EMPRESAS PRIVADAS}

El éxito de las instituciones nacionales, la disponibilidad de tecnología y apoyo técnico y la creciente demanda de tubérculossemillas nacionales de buena calidad, promovieron el interés de empresas privadas nacionales e internacionales en el ramo de la producción de tubérculos-semillas. 
Después de 1978 y más intensamente a principios de la década del 80, se han registrado los siguientes casos o tipos de empresas en especial en los países del Cono Sur:

- Empresas extranjeras en un país de la región. Este es el caso de la empresa Productora de Semillas S.Z. Ltda., radicada en el Sur de Chile. Esta empresa de capital holandés, está vinculada desde 1978 a la Coop. de Z.P.C. de Holanda y asociada a la Sociedad Nacional de Agricultura de Chile. Produce, tanto para Chile como para exportación a otros países de Latinoamérica, tubérculossemillas de variedades patentadas en Holanda. Otras empresas holandesas tienen interés de establecerse en otros países del Cono Sur, principalmente en Argentina y Uruguay.

- Empresas Cooperativas Nacionales. El ejemplo más sobresaliente es la Cooperativa Agrícola de COTIA del Brasil. Esta Cooperativa fundada en 1927 por productores de papa, ha tenido desde sus orígenes una vinculación muy estrecha con la producción de tubérculos-semillas de papa. Las actividades de esta empresa con relación a papa han estado muy vinculadas a la producción de semilla certificada y básica a través del Servicio de Producción de Sementes Básicas (SPSB) de la EMBRAPA con sede en Canoinhas SC. A fines de 1987, esta cooperativa estaba construyendo la infraestructura necesaria (laboratorios e invernaderos, etc.) para iniciar en breve la producción de tubérculos-semillas de categoría prebásica. La evolución de producción de esta semilla en el Brasil está muy vinculada a la dedicación de esta cooperativa.

- Empresas productoras de tubérculos-semillas de categorías básica y prebásicas. Hasta 1982 estos rubros eran producidos en mayor cantidad por empresas estatales o paraestatales como es el caso de "La Pampa" INIA, "Coronel Pringles" en el Sureste de la Provincia de Buenos Aires y más recientemente en una nueva finca en el Partido de Loberías. Estas instituciones se mantienen produciendo tubérculos-semillas de categoría básica y algunas de ellas iniciaron hace algunos años la producción en la categoría prebásicas. Este es el caso de SPSB en Canoinhas, Brasil que produce estas categorías mediante tuberculillos generados de material in vitro en otras unidades de la EMBRAPA, en especial en el CNP-Hortalizas, Brasilia. En años más recientes, a partir de 1984-85, varias empresas privadas principalmente del Brasil y Argentina han iniciado la producción de tubérculos-semillas de categoría prebásica, usando técnicas de multiplicación in vitro y en áreas protegidas contra áfidos (telados o invernaderos). Una de las primeras empresas productoras de semilla fue PILPOT 
S.A. de la Argentina, la cual inicialmente importó minitubérculos desde California (EE.UU.), produjo tubérculos-semillas para su propio uso en invernaderos importados de plástico de paredes inflables. Otras empresas argentinas con producción de plántulas in vitro locales y en telados son: Atlántida Semillas, Agrogenética S.A., Lastra y Cía., Hernández y Cía., entre otras. Todas ellas producen sus propios materiales.

- Entre las empresas brasileñas productoras de semillas están: Biomatrix S.A., Bioplanta Tecnología de Plantas Ltda., Sociedade Brasileira de Sementes (SBS-Biotecnología e Produção Agrícola Ltda., y la Empresa de Produçao Agropecuaria LTDA. Las dos primeras empresas generan sus propios materiales a partir de cultivos in vitro y la empresa Bioplanta a su vez produce sus tubérculos-semillas de las categorías básica y certificada mediante contratos con productores.

- Otra modalidad reciente de participación de empresas privadas es la posible integración de empresas de tipo binacional. A finales de 1987, una empresa de este tipo estaba en proceso de formación por una empresa Argentina y otra del Brasil. Se prevé que se producirán algunas etapas de las semillas pre-básicas y básicas en uno de los países con mejores ventajas comparativas para hacerlo.

- Finalmente, desde 1983 está establecida en Mar del Plata, Argentina, la empresa privada Diagnósticos Vegetales S.R.L. en el ramo del diagnóstico de virus durante el cultivo y en postcosecha, análisis de nematodos en suelo y en tubérculos y contaje de pulgones a través de trampeos. Esta empresa está autorizada por la Secretaría de Agricultura de la Argentina para efectuar análisis de muestras cuyos resultados reconoce el Servicio de Fiscalización, para efectos de certificación de semillas.

- Otras empresas privadas de los países del Cono Sur están igualmente interesadas en el rubro de diagnósticos y también en la producción de antisueros y conjuntos serológicos. Existen muy buenas perspectivas de inversión en estas áreas.

Sin lugar a dudas, las empresas privadas han contribuido significativamente al mejoramiento de la producción de semilla en los países del Cono Sur. La libre competencia y la capacidad técnica de cada una determinará el futuro progreso de las mismas. 
Dentro de la actividad privada es necesario reconocer el significativo aporte de los productores de semilla, individuales o agrupados en asociaciones de productores. Casi invariablemente en cada zona productora de tubérculo-semilla, existe ya una asociación de productores de semilla, los cuales en alguna medida determinan el desarrollo de la actividad.

\section{CONCLUSIONES Y PERSPECTIVAS}

Se han registrado progresos significativos en la producción de tubérculos-semillas de papa en Latinoamérica, lo cual está llevando a la autosuficiencia de producción y a una reducción rápida de las importaciones. Las decisiones políticas de los países de reducir gradualmente sus importaciones o crear e impulsar los programas de tubérculo-semilla han permitido un acelerado proceso de desarrollo, el cual ha sido favorecido por la investigación, disponibilidad de tecnología, asistencia técnica y capacitación en las áreas prioritarias y a la decisión en el rubro de semilla.

El rol de las instituciones internacionales como el CIP y de las instituciones de cooperación económica y técnica internacionales, han favorecido la transferencia de tecnología y el establecimiento de programas de tubérculos-semillas en la mayoría de los países latinoamericanos.

Pese al rápido desarrollo, hay aún mucho por hacer para resolver problemas técnicos y económicos que ocurren al aumentar la producción. Se hace necesario por ejemplo cuidar mejor las "nuevas" áreas o zonas de producción de tubérculos-semillas en Argentina y Brasil. Una mejor aplicación de reglas sanitarias más estrictas podría proteger mejor esas áreas, evitando la introducción de plagas y enfermedades o el aumento de otras, que bajo condiciones normales no serían factores limitantes. También se hace necesario llevar a cabo estudios agrosocioeconómicos que permitan definir las necesidades nacionales de tubérculos-semillas, para calcular adecuadamente los volúmenes de semilla y de servicios requeridos que las empresas deberían producir y ofrecer respectivamente.

Es fundamental continuar con el apoyo a las empresas privadas con el fin de favorecer la creación de las que sean necesarias o de fortalecer la existentes para hacer más eficiente la producción de tubérculos-semillas y en alguna medida reducir el costo de la misma, la cual pese al avance alcanzado es aún el insumo más caro del cultivo de papa. Finalmente, se necesita que los organismos nacionales e internacionales continúen sus trabajos de 
investigación, asistencia técnica y capacitación sobre tubérculosemilla. Mediante estos mecanismos de acción ha sido posible lograr los progresos en la producción de tubérculos-semillas de papa en Latinoamérica, por lo cual deben ser mantenidas y aumentadas las inversiones que se hagan en la actualidad en investigación. Invertir en semilla ha sido y seguirá siendo una actividad rentable y provechosa para cada país.

\section{Agradecimientos}

El autor expresa su agradecimiento y gratitud por la asistencia prestada en la preparación y revisión del manuscrito a los siguientes colegas latinoamericanos: Carlos Crisci (Uruguay), Cesar Vittorelli (Perú), Elcio Hirano (Brasil), Ivan Butzonitch (Argentina), José Santos Rojas (Chile), Manuel Villarreal (México), Roberto Rodríguez (Panamá), Martha de Duque (Colombia), así como a los colegas Hernán Rincón, James E. Bryan, Fernando Ezeta y Primo Accatino del CIP. Los avances en la producción de tubérculosemilla de papa en Latinoamérica se deben sin lugar a dudas a la dedicación de éstos y muchos otros investigadores latinoamericanos.

\section{Summary}

Progresses on potato tuber seed production in Latinamerica. O. A. Hidalgo. Int. Potato Center. A.A. 92654. Bogotá 8 D.E., Colombia.

Significant progresses on potato tuber seed production in Latinamerica are noticed after contrasting and analyzing the situation and technologies used in the seed programs in a 12 year period (1975-86). By 1975 most of the Latinamerican countries (with exception of Chile and México) had poorly seed developed programs. In those countries where the subspp. tuberosum was grown, seed programs were based almost entirely on tuber-seed imports. In the Andean countries (subspp. andigena) however there were incipient and informal seed certification programs. Programs of Chile and México were based on imports but good seed quality was maintained by using the traditional clonal system. In a 12-year period (by 1987) most of the countries in Latinamerica have had implemented well developed programs and locally produced prebasic and certified seed have had increased substantially. Rapid progress obtained by the national seed programs are explained by the support received through appropriate governmental decisions and by the massive use of new technologies in vitro tissue 
culture, rapid multiplication techniques, the extensive use of serological techniques, etc.

The intensive training programs carried out by the National Programs and CIP in all Latinamerican countries in the last decade have positively influenced in these developments. Role of governmental decisions on reduction of seed imports as well as the promotion of local seed programs in the private sector are also discussed with special emphasis in the different types of private organization generated in three South Cone countries (Brazil, Argentina and Chile). Progresses in Central America, México and Panama and in the Andean countries are also discussed based on programs developed with the support of international organizations and CIP.

\section{REFERENCIAS BIBLIOGRÁFICAS}

1. Bryan, J. E. 1988. Implementation of rapid multiplication and tissue culture methods in third world countries. Am. Potato J. 65: 199-207.

2. Cobarrubias, C. 1984. Estudio agroeconómico de la producción y uso de semilla certificada de papa en Chile: Resultados de una encuesta a agricultores. Proyecto INIA/CIP. Santiago Chile. 98 p. (Mimeografiado).

3. Empresa de Ingenieros Consultores. 1979. Estudio de mercadeo de exportación de semillas de papa. Informe Técnico (Capítulos 1 al 15) preparado para la Secretaría Regional de Planificación y Coordinación de la X Región (Chile).

4. Guerrero, H. 1986A. Implementación y desarrollo de programas de producción de semillas de papa en países tropicales. En: "Taller de Trabajo sobre Producción de Semilla Comercial de Papa" CIP-Lima 3-7 Marzo 1986 Mimeo 11 p.

5. Guerrero H. 1986B. Organización de la producción de semillas de papa en República Dominicana. En: "Taller de Trabajo sobre Producción de Semilla Comercial de Papa" CIPLima 3-7 Marzo 1986. Mimeo. 11 p.

6. Hidalgo, O. A.; Accatino, P. 1985. O Centro Internacional de la Papa e sua contribucão para os programas de batata dos países ñao andinos da América Latina. Horticultura Brasileira 3:3-12.

7 Horton, D. E.; Fano, H. 1985. Atlas de la Papa. Centro 
Internacional de la Papa. Lima-Perú. 135p.

8. Monares, A.; Rojas, J. S.; Cobarrubias, C.; Kalazich, J.; Gugliemetti, H.; Hidalgo, O. 1988. Producción y utilización de tubérculos-semillas de categoría certificada en Chile. Un estudio agroeconómico INIA-CIP. Centro Internacional de la Papa. Lima, Perú. 160 p.

9. Naranjo, H.; Estrella, D. 1987. "Modelo INIAP": Una técnica de multiplicación rápida de papa. Estación Experimental Sta. Catalina-INIAP. Quito, Ecuador. 12 p. (Boletín Divulgativo, No. 196).

10. Niño de Gualdrón, L. 1988. Producción de semilla de papa en Venezuela En: Curso Internacional sobre el Cultivo de la Papa. CIP-Lima, Perú. p. 162-205.

11. Rojas, J. S. 1986. El Programa Chileno de papa-semilla certificada: estructura, relaciones y operación. En: Taller de Trabajo sobre Producción de Tubérculo Semilla Comercial de Papa". CIP-Lima. 3-7 Marzo 1986. Mimeo. 37 p.

12. Villarreal, M. J. 1987. Producción de tubérculo-semilla comercial de papa en México, p. 8-15. En: I Seminario-Taller de Trabajo "Producción de Tubérculo Semilla Comercial de Papa". PRECODEPA/CIP. Marzo 3-11, 1986. Lima, Perú.

13. Vittorelli, C.; Hidalgo, A.; Auroi, C. 1987. Producción y difusión de tubérculo-semilla comercial en el Perú. p. 42-52. En: Seminario-Taller de Trabajo "Producción de Tubérculo Semilla Comercial de Papa". PRECODEPA/CIP. Marzo 3-11, 1986. Lima, Perú. 